\title{
A DIMENSÃO ÉTICO-POLÍTICA DA HUMANIZAÇÃO E A FORMAÇÃO DE APOIADORES INSTITUCIONAIS
}

\author{
THE ETHICAL AND POLITICAL DIMENSION OF HUMANIZATION AND THE TRAINING OF \\ INSTITUTIONAL SUPPORTERS
}

\author{
LA DIMENSIÓN ÉTICO-POLÍTICA DE LA HUMANIZACIÓN Y LA FORMACIÓN DE \\ APOYADORES INSTITUCIONALES
}

\author{
Maria Claudia Souza Matias ${ }^{1}$ \\ Marta Inez Machado Verdi ${ }^{2}$ \\ Mirelle Finkler ${ }^{3}$
}

Resumo Ao se afirmar como política pública fundamentada no paradigma ético-estético-político, a Política Nacional de Humanização introduz um novo sentido para a proposta de humanização da saúde: um sentido contra-hegemônico, associado à compreensão da vida como abertura e multiplicidade. Em face do desafio de operar um conceito tão inovador e contrário às práticas tradicionais, este estudo buscou discutir o entendimento e a vivência que apoiadores institucionais formados pela Política Nacional de Humanização tinham da dimensão ético-política contida na proposta. O objeto desta pesquisa foi investigado à luz de abordagem metodológica qualitativa, de caráter exploratório-descritiva, tendo como sujeitos os egressos de um processo de formação de apoiadores institucionais realizado em 2009 em Santa Catarina. Por meio de entrevistas e pesquisa documental, obtiveram-se como resultados uma compreensão da dimensão fundamentada na valorização dos sujeitos e na democratização das relações. As vivências e experimentações, entretanto, foram marcadas por obstáculos e desafios, como o da concentração de poder nas instituições e o da fragilidade do modelo de atenção à saúde, ainda pautado nas racionalidades gerencial e biomédica. Também se interpuseram como desafio dificuldades relacionadas à compreensão de alguns conceitos da Política e aos modos como tem se organizado nos serviços de saúde e interfederativamente.

Palavras-chave ética; política de saúde; humanização da assistência; educação em saúde.
Abstract By establishing itself as a public policy based on the ethical-aesthetic-political paradigm, the National Humanization Policy introduces a new sense to the proposal of humanizing health: A counter-hegemonic sense, coupled with the understanding of life as openness and multiplicity. Given the challenge of operating such an innovative concept, which is contrary to traditional practices, this study sought to discuss the understanding and experience that institutional supporters trained under the National Humanization Policy had of the ethical and political dimension of the proposal. The subject of this research project was investigated in the light of a qualitative methodological approach, exploratory and descriptive in nature, having as subjects the graduates of an institutional supporter training process held in 2009, in Santa Catarina, Brazil. Through interviews and documentary research, the results were the obtained of an understanding of the scale based on the valuation of subjects and democratization of relations. The experiences and tests, however, were marked by obstacles and challenges, such as the concentration of power at the institutions and the fragility of the health care model, still guided by management and biomedical rationales. Also challenging were the difficulties related to the understanding of a few of the concepts of the Policy and the ways in which it has been organized both in health services and inter-federatively.

Keywords Ethics; health policy; humanization of assistance; health education. 


\section{Introdução}

O movimento pela humanização da saúde não é recente. Fruto, dentre outras, das lutas iniciadas na década de 1960, em torno do debate feminista pela saúde da mulher, o movimento vem ganhando corpo nas últimas décadas. No início dos anos 2000, desconectado dos movimentos instituintes que o engendraram, aparece associado a práticas de saúde que reproduziam sentidos de humanização incapazes de acionar reais mudanças nos modos de fazer na saúde. A proposta do extinto Programa Nacional de Humanização da Assistência Hospitalar (PNHAH) surge com o intuito de promover a ampliação do processo comunicacional (Deslandes, 2004), não conseguindo, no entanto, interferir nas práticas metrificadas com origem em uma concepção idealizada do humano.

Assim, um dos maiores desafios enfrentados pela Política Nacional de Humanização (PNH), proposta em 2003, é o de fazer coincidir as práticas em humanização na saúde com o sentido conferido por esta Política ao termo. À PNH coube redefinir o conceito e buscar a crítica e a interferência nas práticas segmentadas por área e nível de atenção, relacionadas a determinadas profissões e ao gênero feminino, e balizadas por noções de mercado que colocavam o 'cliente' como foco das ações, pautando critérios padronizados de qualidade a serem aplicados indistintamente (Benevides e Passos, 2005). Insistindo no termo, mas apartando-o da idealização do homem e de práticas, o humano evocado pela $\mathrm{PNH}$ é o humano concreto, valorizado em suas singularidades e diferenças, descolado de padronizações às quais não corresponde nenhuma existência concreta. O modo proposto pela $\mathrm{PNH}$ de fazer operar este sentido de homem desidealizado é o da inclusão dos diferentes sujeitos. Para os trabalhadores, esta acepção implica a criação de outra posição nas organizações, distinta do lugar usualmente conferido pela gestão tradicional: subjugados pelo controle ou subestimados pelas prescrições do seu trabalho (Brasil, 2008; Benevides e Passos, 2005; Pasche, Passos e Hennington, 2011).

A humanização, assim proposta pela $\mathrm{PNH}$, inscreve-se como conceito-experiência, que busca descrever, intervir e produzir realidade a partir das experiências e sujeitos concretos, com características diversas do modelo científico na construção do conhecimento: o paradigma ético-estético-político (Guattari, 1992), constituído por estas três dimensões indissociadas. A dimensão ética é aquela que busca a potência derivada das práticas que visam coordenar a vida e escolher a forma de vivê-la, marcada pela escuta das diferenças e pelo que estas produzem em nós. A estética seria dada pela possibilidade de criação permanente, que encarna as marcas do pensamento e que engendra novas formas de subjetivação. A dimensão política estaria associada à possibilidade de escolha de modos de organizar o mundo em que se 
quer viver e, segundo Rolnik (1993), estaria focada na luta contra as forças que obstruem as possibilidades do devir.

Para a PNH, a dimensão ética deste paradigma se corporifica a partir de uma proposta de humanização que considere a premissa do reconhecimento do outro, de suas diferenças e de seus modos de viver, e do comprometimento com o respeito a estas diferenças que nos singularizam como sujeitos, marcando a expressão de nossa humanidade. Nesse sentido, aparece vinculada à defesa da vida e ao direito ao desenvolvimento integral como valores norteadores para as ações em saúde. A dimensão estética na humanização é dada pela busca de processos sensíveis de invenção de estratégias que contribuam para a produção a dignificação da vida, por práticas mais efetivas de produzir saúde. E a dimensão política do paradigma é situada na PNH na proposta de discussão das relações de poder e da democratização institucional, com base na aposta em modos de organizar as instituições e a sociedade que estejam comprometidos com o protagonismo dos diferentes sujeitos (Brasil, 2008).

No entanto, escolhas que reflitam novos modos de subjetivação e que envolvam a forma como o mundo se organiza e a escuta das diferenças são propostas contra-hegemônicas em nossa sociedade. Historicamente a saúde tem majoritariamente valorizado, compreendido e organizado suas práticas pelas lentes do paradigma científico e de outros sistemas correlacionados de pensamento e organização da realidade, como a racionalidade médica e as práticas tradicionais de gestão, obstaculizando acentuadamente os modos contra-hegemônicos de pensar e de fazer. Para enfrentar tal cenário e para sustentar uma proposta afinada a esse paradigma, a PNH tem buscado criar estratégias que confiram materialidade aos valores e premissas associados a essas dimensões do paradigma. A formação de apoiadores institucionais tem sido um dos principais focos da ação da política, por entender o apoio como função que pode assumir posição estratégica para a mudança de modelo de atenção e de gestão no Sistema Único de Saúde (SUS). O apoio se volta ao fomento e acompanhamento de processos de mudança nas organizações, mobilizando diferentes atores (gestores, trabalhadores e usuários) em torno da tarefa de construção de projetos cogeridos que atendam à necessidade desses diferentes grupos de interesse, bem como as de superação sanitária (Campos, 2000; Heckert, Passos e Barros, 2009; Pasche e Passos, 2010).

Os processos de formação de apoiadores vêm se efetivando na PNH desde 2006, tendo a formação-intervenção como metodologia, coerentemente com os princípios, as diretrizes e os dispositivos da PNH. O primeiro curso voltado à formação de apoiadores institucionais ajudou a consolidar as diretrizes que essa Política viria a adotar para suas ações de formação. Estas têm se fundamentado, desde então, na metodologia da formação-intervenção, que 
propõe aos participantes experimentarem a construção e implementação de um plano de interferência nas práticas de saúde ainda no decurso da formação. A conexão de usuários, trabalhadores, gestores e movimentos sociais na análise da realidade para a transformação das práticas e a produção de redes também é fomentada nesse percurso formativo. Desse modo, constitui-se como um dispositivo tanto de produção de conhecimento quanto de sujeitos e de práticas (Pavan et al., 2010; Heckert, Passos e Barros, 2009; Pasche e Passos, 2010).

$\mathrm{Na}$ maioria dos processos de formação organizados pela $\mathrm{PNH}$, o exercício da função apoio tem sido priorizado. O apoio é uma estratégia que nos últimos anos vem sendo experimentada mais intensivamente no SUS. Com base em práticas diversas, vem evidenciando o agenciamento de sujeitos e processos em torno da proposta da democratização institucional. Na PNH, o apoio se refere à atuação junto a coletivos da saúde, na busca da construção de objeto e objetivos comuns, que sustentem ações construídas e geridas coletivamente, como modo de fomentar e acompanhar processos de mudança nas organizações (Oliveira, 2011).

Assim, a proposta de formação de apoiadores institucionais ratifica uma produção do cuidado em saúde articulada a escolhas ético-políticas, pautadas no acolhimento à diversidade da vida que se expressa na ideia de saúde como multiplicidade (Paulon e Carneiro, 2009). Se entendermos a formação como instituição, ou seja, representante de certo conjunto de práticas sociais historicamente produzidas, que constrói verdades, objetos-saberes e modos de subjetivação, ela reveste-se de outra relevância: a possibilidade de poder problematizar o mundo e os modos de subjetivação existentes, as formas pelas quais nos constituímos como sujeitos, portadores de crenças, valores, opiniões, modos singulares de ser e de estar em relação. Nesta acepção, percebemos que a formação pode provocar movimentos de desestabilização e interferir na produção de subjetividades e de práticas (Barros, 2006; Fuganti, 1990). Esse modo de formar, por também fundamentar-se no paradigma ético-estético-político, apresenta-se como abordagem pedagógica coerente com a proposta da PNH.

O bioeticista italiano Giovanni Berlinguer, na obra Medicina e politica (1987, p. 5), aponta a necessidade de que a saúde fomente o desenvolvimento de uma consciência sanitária, “a tomada de consciência de que a saúde (...) é um direito da pessoa e um interesse da comunidade", e frisa: "como este direito é sufocado e descuidado, consciência sanitária é a ação individual e coletiva para alcançar este objetivo". Essa educação sanitária seria ação voltada também à população de modo geral, sendo os profissionais da saúde sujeitos que teriam importante função nesta tarefa, ao fomentarem experiências formativas que articulassem os movimentos organizados dos trabalhadores aos movimentos organizados dos cidadãos. A formação de uma nova cons- 
ciência sanitária, segundo Berlinguer, seria premissa para formação de uma consciência social entre os profissionais da saúde, havendo a necessidade de que tanto a saúde coletiva quanto a formação desses profissionais passasse por uma reforma, que conferisse organicidade e continuidade à educação sanitária de massa e à formação social dos trabalhadores sanitários.

O pensamento de Berlinguer, um dos atores responsáveis pela reforma sanitária italiana, sustenta a necessidade de que busquemos superar os desafios de formulação de um novo modo de produzir práticas de saúde indissociado de uma perspectiva ético-política. Considerando isto e, assim, o consequente desafio de operar o conceito de humanização proposto pela PNH, este estudo buscou discutir a compreensão e a vivência que egressos de um curso de Formação de Apoiadores Institucionais realizado em 2009, no estado de Santa Catarina, tinham da dimensão ético-política da humanização. A proposta se ampara no entendimento de que para a sustentabilidade da política pública faz-se necessário estudar os processos de formação que hoje buscam no SUS indissociar o técnico-tecnológico de uma perspectiva ético-política.

\section{Percurso metodológico}

Este estudo 4 foi parte de uma pesquisa maior, multicêntrica e interinstitucional, 5 de caráter avaliativo, que teve como objeto os efeitos dos processos de formação da PNH na produção de saúde no SUS, em Santa Catarina, Rio Grande do Sul e São Paulo. O estudo envolveu sujeitos que pertenciam às duas macrorregiões de saúde do estado mais próximas das pesquisadoras. Dos 21 apoiadores formados nos dois territórios, 13 responderam ao convite e 11 efetivamente participaram do estudo. Estes 11 apoiadores tinham em média 12 anos de trabalho no SUS, todos possuíam especialização ou mestrado na área da saúde, e dez deles eram enfermeiros ou assistentes sociais. E em 2012, período da coleta dos dados, a maioria atuava em hospitais e ainda estava na mesma instituição em que atuava à época do curso. Alguns deles já tinham envolvimento com a humanização previamente ao curso, e quase todos se inscreveram no curso por iniciativa pessoal.

A coleta dos dados foi realizada cerca de dois anos após a conclusão da formação dos apoiadores, por meio de pesquisa documental e entrevistas semiestruturadas. A pesquisa documental analisou os relatos de conclusão de curso, que retratavam o plano de intervenção produzido ao longo da formação. As entrevistas foram gravadas e transcritas, abarcando questões elaboradas a partir dos sentidos atribuídos pela PNH à dimensão ético-política da humanização em suas publicações e que versam sobre a produção de autonomia, protagonismo e corresponsabilidade entre os sujeitos, o direito ao desenvolvimento integral 
e a democratização das relações. Nas entrevistas, buscou-se investigar as compreensões e as vivências desses sujeitos quanto a esses sentidos, desde sua passagem pela formação de apoiadores institucionais. Com o auxílio do software Atlas-ti ${ }^{\circledR}$, os dados transcritos foram organizados, codificados e sistematizados em categorias, conforme a análise temática proposta por Bardin (2010).

As diferentes implicações da pesquisadora principal com o objeto estudado (coordenação do curso realizado em Santa Catarina) foram consideradas ao longo de toda a pesquisa, como modo de garantir sua cientificidade. A pesquisa implicada não dissocia o objeto investigado do sujeito que investiga, tratando a subjetividade desde a perspectiva do paradigma ético-estético-político, que busca singularizar as experiências humanas, em vez de generalizá-las, em um compromisso social e político com a realidade investigada (Paulon e Romagnolli, 2010).

Para a análise dos resultados, procuramos promover um diálogo entre a proposta da PNH e a bioética social, campo da bioética que se volta à discussão do que seja a produção do bem comum no cotidiano da saúde, problematizando temas como o das desigualdades como fator de produção de doenças, o da saúde como direito coletivo e dever do Estado, o do respeito ao pluralismo moral e cultural, o da autonomia e o do empoderamento dos sujeitos (Berlinguer, 1996). A bioética entende a saúde e a doença como processos inseridos no campo universal da experiência, da reflexão e das escolhas morais, e por esta razão tem sido apontado como referencial adequado à análise crítica acerca da moralidade das políticas públicas na área da saúde, bem como para a tomada de decisões eticamente justificadas (Schramm e Arreguy, 2005).

O projeto, aprovado pelo Comitê de Ética da UFSC sob o n. 21561/2012, não teve conflito de interesses. Somente após a aprovação do comitê e a anuência da Escola de Saúde Pública, órgão executor do curso e responsável pelos documentos da pesquisa documental, os apoiadores foram convidados a participar do estudo. Sua adesão foi voluntária, tendo-se assegurado os direitos a: se retirarem da pesquisa em qualquer etapa do estudo; terem resguardado o sigilo das identidades; acessarem os resultados da pesquisa; participarem do processo de consentimento livre e esclarecido, bem como todos os demais aspectos éticos mencionados na resolução n. 196/96 do Conselho Nacional de Saúde. O anonimato foi preservado e mantido por meio da adoção de codinomes, evitando-se assim uma possível identificação dos entrevistados.

\section{A dimensão ético-política da humanização no discurso dos apoiadores}

Escutar os apoiadores formados em 2009 e reler seus planos de intervenção foi uma experiência que provocou um deslocamento no modo como entendíamos 
a formação para a humanização e a própria função apoio. As falas apresentadas a seguir apresentaram as aproximações esperadas com a temática do estudo, mas também explicitaram alguns dos fatores que vêm interferindo na formação de apoiadores e na própria expansão da PNH nos territórios. Tais fatores são entendidos aqui como linhas de força que ora sustentam o desejo em torno da consolidação de uma política pública de saúde afinada com as proposições discursivas do SUS, ora sustentam a trama de concepções hegemônicas e de modos de reprodução de instituídos na saúde. Assim, destacamos os principais temas que conformaram as compreensões e vivências dos apoiadores entrevistados quanto à perspectiva ético-política para a humanização da saúde, e as dificuldades e insuficiências relacionadas.

Temas como o das relações sujeito-sujeito, a defesa do direito ao desenvolvimento integral e a reflexão sobre o agir ganharam relevância na fala dos sujeitos. Abarcaram sentidos que enfatizavam o valor das relações entre sujeitos que se reconhecem enquanto tal, em relações horizontais que se estabelecem pelo exercício da alteridade, refutando qualquer possibilidade de tomar o outro como objeto. Destacaram-se também nessas falas a defesa do direito à diferença como aspecto a ser assegurado e valorizado por ser central no processo de produção de saúde, com base em práticas agenciadoras, que colocam os sujeitos em relação.

A PNH busca esse compromisso de envolver-se nesse acompanhar e orientar, tendo assim ética no que se refere ao compromisso com o reconhecimento do outro, na atitude de acolhê-lo em suas diferenças, dores, sentimentos e modo de encarar a vida (Tales).

(...) o sujeito deveria ser considerado um sujeito de afetos, de escolhas, de uma história (...) num contexto, num território (Empédocles).

O reconhecimento do outro e inclusão dos afetos aparecem também como sentidos que apontam para uma compreensão da dimensão ético-política direcionada à inclusão dos sujeitos, coletivos e analisadores sociais que, quando expressos nas crises e perturbações, possibilita que nos defrontemos com a alteridade, podendo nos conduzir a um reposicionamento subjetivo (Heckert, Passos e Barros, 2009). Zoboli (2009) afirma que todo compromisso, reflexão e conduta ética estão fundamentados na dignidade da pessoa, sendo o exercício da alteridade o que nos permite corrigir uma visão individualista e abstrata, resgatando o sujeito concreto. A alteridade se dá quando estamos diante do outro, em uma relação de proximidade que possibilita revelar não o modo alienado como ele está no sistema, mas o modo como poderia e mereceria estar, por sua condição de pessoa digna e livre.

Foi possível localizar nos planos de intervenção registros desse processo de reposicionamento de alguns apoiadores frente ao tema da alteridade. 
Em muitos casos, aparece também o desconforto experimentado diante de formas novas de ver e relacionar-se com o outro, evidenciando nestas descobertas a dimensão de sofrimento associada.

Como é gratificante ver as diferenças entre nós e como é doído admitir que o outro seja melhor [no atendimento ao usuário] e que, se eu quiser ser parecido com ele, tenho que mudar (...) vou me fortificar com aquele que eu achava que não tinha nada a me ensinar (Plutarco).

(...) produziu uma certa vontade de mudança, me senti muito incomodada com o processo de trabalho em que estava inserida, passei por algumas mudanças em meu interior (Tales).

É necessário produzir estranhamento quanto às formas totalizantes de compreender e atuar das políticas públicas. Políticas pautadas na experimentação e em novos modos de ser e de estar em relação são atravessadas pela noção de bem comum, uma produção de valor realizada em bases éticas que inviabilizam sua privatização, que a restringiria a interesses individuais. O modo pelo qual a alteridade tem sido vivenciada nas políticas de saúde interfere radicalmente na própria concepção de política presente na trajetória do SUS, onde a regra tem sido a da reprodução de práticas de gestão hegemônicas que percebem a alteridade como elemento antagônico. Mesmo quando se defende o contrapoder no SUS, observamos nos projetos e intencionalidades modos de produção totalizantes, que disputam entre si. Nesta lógica, a política torna-se campo de aniquilação, onde o que difere de mim tem de ser vencido (Guizardi e Cavalcanti, 2009).

Outro sentido observado nas falas desses sujeitos foi o da produção de comum como produto de diálogo, reflexão, vínculo e reinvenção dos modos de fazer, sendo os conflitos parte desta produção.

Na primeira roda de conversa foi uma lavagem de roupa suja, os administradores não gostaram, e nós mostramos que era um espaço político aberto, ético, onde podíamos falar nossos desejos e frustrações (...) um espaço político de discussão, de decisão conjunta (Demócrito).

Como produção social, o bem comum resulta de um processo de interseção entre práticas, instituições e dispositivos - técnicos, comunicacionais, organizacionais - que afetam e são afetados, produzindo subjetividades alicerçadas em uma ética que combate a exploração ou o cerceamento da vida. O bem comum produz relações e práticas de liberdade e igualdade, entendendo-se esta última como condição de legitimidade do direito dos sujeitos à diferenciação (Guizardi e Cavalcanti, 2009). 
Os vínculos e relações solidárias são colocados por Heckert, Passos e Barros (2009) como base para uma ética da alteridade, que não acontece apartada do mundo em que criamos e convivemos. Assim, a humanização desloca-se do campo de uma moral que faz escolhas entre o bem e o mal, posto que acentua o processo de produção de subjetividade, onde os vínculos entre os sujeitos não se efetuam fora do plano das práticas de cuidado e de gestão.

Ayres (2009), ao analisar a proposta da $\mathrm{PNH}$, localiza uma resposta efetiva, um caminho, para a proposta da presença da ética no âmbito do SUS. Tal ética, sem estar atrelada a qualquer tipo de principialismo ou formalismo, fundamenta-se no reconhecimento da centralidade da palavra e do diálogo, como modo compartilhado de construir uma atenção à saúde universal, equânime e integral, entre sujeitos plenos de direito. O tema do 'direito ao desenvolvimento integral' apareceu de modo recorrente no discurso dos apoiadores, acentuando questões como a defesa do SUS, a mudança do modelo de atenção e a valorização do trabalho e do trabalhador.

Desenvolvimento integral não é só aquela atividade de trabalho, mas um desenvolvimento intelectual. Não é só técnica, técnica. Expandir, fazer mais cursos, estudos (...) e que nossos funcionários pudessem participar, não só aquela coisa fechada em técnica (Parmênides).

Ao se colocar o desenvolvimento integral dos sujeitos como valor, uma das premissas em jogo é a de que as organizações, além de produzirem bens ou serviços de interesse social, devem assegurar a sobrevivência da própria organização e do conjunto de agentes que a integram, incluindo aí a realização financeira, profissional e pessoal de toda a gente que nela trabalhe ou dela dependa (Campos, 2000). Transpondo-se esta afirmação para a saúde coletiva, o autor afirma que as organizações a ele vinculadas devem buscar garantir a realização profissional e pessoal dos trabalhadores, para além do compromisso com a produção de saúde (seu valor de uso) e a reprodução do SUS como política democrática e solidária.

Outra premissa que se associa ao direito ao desenvolvimento integral dos sujeitos é a da própria integralidade da atenção, considerando que o SUS vem colocando o tema dos direitos e das responsabilidades como vinculados ao próprio cuidado em saúde. Neste sentido, a ética do cuidado vincula direitos às responsabilidades, sendo as relações intersubjetivas o plano legítimo onde ela se dá (Zoboli, 2009).

Os modos instituídos são alvo da percepção crítica dos apoiadores. As prescrições normativas têm sido apontadas muitas vezes como barreiras ao cuidado responsável e à defesa dos direitos dos usuários. 
Regras não são sempre corretas. Tem aquela mãe que chega depois, têm as crianças que a mãe tá lá dentro, (...) acontece isto em todo lugar. As coisas que fogem da regra. A gente pensa enquanto ser humano (Antístenes).

Neste sentido, a experiência da humanização evoca uma concepção de saúde como experiência de criação de si e de modos de viver (Neves e Massaro, 2009). Isto implica reafirmar a vida como movimento incessante de produção de normas, que se dá a partir de exigências que se atualizam cotidianamente e que quase nunca coincidem com as prescrições reificadas do cotidiano institucional. A soberania do direito à saúde sobre as regras e normas institucionais é sustentada também na luta jurídico-política por este direito, que inicia quando a saúde deixa de ser vista como necessidade humana, quase sempre impossível de ser plenamente atendida, e é alçada ao patamar de direito (Berlinguer, 1996).

Tais condições fundamentaram o pensamento que a saúde é algo passível de ser transformada, fundamentada na experiência - uma ideia laica, que substituiu as antigas ideias sacras que associavam a saúde às determinações do destino e à expiação de culpas. Esta nova concepção originou o princípio moral que a coloca como um valor em si mesmo (Berlinguer, 1996). $\mathrm{Na}$ fala dos apoiadores isto aparece associado à defesa do SUS, à ideia de humanização como causa justa, mas atravessada por muitos obstáculos:

Sei o quanto não foi fácil chegar até aqui, todas as vezes que desanimei, procurei encontrar forças dentro de mim, por saber que é uma causa justa e, por uma busca incessante por um SUS melhor (Tales).

Aqui se evidencia a proposta de 'consciência sanitária' de Berlinguer (1987), que sustentaria a formação de outra consciência social quanto à saúde. O apoiador fala de 'luta' e define a causa como 'justa'. Esses sentidos são particularmente importantes porque, diferente de outros direitos, para os quais a simples não interferência da sociedade é suficiente para garanti-los, a saúde é um direito positivo. Em outras palavras, para promovê-lo é necessário que a sociedade ponha em curso uma ampla e complexa gama de benefícios e condições, criando obrigações sociais até bem pouco tempo inexistentes e que não são facilmente garantidas por leis. Tal análise ajuda-nos a compreender, em parte, a distância existente entre o regime discursivo do SUS e as práticas concretas que tem conseguido sustentar. Para Zoboli (2010), a consolidação do SUS é tarefa ética, pois os limites do possível não podem ser dados pelo que já existe. Significa dizer que a defesa dos direitos traduz o imperativo ético de lutar para que o SUS coloque cotidianamente à disposição dos sujeitos aquilo que é essencial para sua cidadania. De fato, como sustenta Pasche (2010), um dos maiores desafios do SUS é a construção de 
uma agenda ética para a micropolítica: o desenvolvimento da discussão sobre as relações entre os diferentes sujeitos, assentadas no cuidado e responsabilização compartilhadas.

Em relação ao tema dos obstáculos a uma maior vivência e compreensão da dimensão ético-política, há falas que aludem ao regime discursivo da própria $\mathrm{PNH}$, que estaria atravessado por excessiva 'teorização', estando essas dificuldades de entendimento associadas a um tempo insuficiente de formação:

(...) é complicado de fazer as pessoas entenderem... até pra gente entender, enquanto profissional. Eu não consigo explicar muita coisa da PNH, que é teórica, e eu não consigo passar pra frente. Se for pedir pra explicar alguns conceitos, eu não consigo (Thales).

Penso que o curso deveria ser mais longo, pois o conteúdo é extenso e merece mais tempo de reflexão e discussão. Hoje me sinto preparada para iniciar o curso de Formação de Apoiadores Institucionais para a Política Nacional de Humanização da Gestão e da Atenção à Saúde (Plutarco).

Tinha coisas que eu não conseguia entender, eu tentava focar, mas parecia que tavam falando uma outra linguagem... Ficou muita coisa que eu não consigo entender. Depois, com uma visão diferente, talvez desse pra compreender, mas seria necessário um outro curso para entender melhor. Ela [a PNH] é complexa de conceitos (Antístenes).

É possível perceber que o processo proposto pela formação - de transformação das práticas a partir de novos modos de olhar para a realidade - não se deu de modo linear. Embora as falas apontassem para um movimento de abertura ao que foi trazido de novo pela política, elas também revelaram compreensões que por vezes não abarcaram a complexidade de seus conceitos-ferramenta, gerando frustração e sentimentos de impotência nos sujeitos. Restou ao apoiador muitas vezes preencher os não entendimentos com as já tradicionais compreensões prescritivas e normatizantes da realidade.

O desconhecimento contribui para a não responsabilização. Se todos estivessem com a mesma sintonia, este nosso processo seria mais redondo, fluiria melhor, não teria tanto conflito sobre o que tem que ser feito. Quando é feito um protocolo, alguns leem, (...) mas alguns não participam, não têm esta responsabilização de se inteirar com as coisas da instituição, não têm um entrosamento legal (Platão).

Cabe avançar no questionamento das razões que levaram a uma compreensão ainda claudicante sobre a humanização e seus conceitos-ferramenta. 
Sá (2009) sugere que os modos idealizados de pensar o funcionamento da sociedade estão por demais entranhados na compreensão dos sujeitos acerca da realidade, além de serem muito sedutores. Quem já não se deixou levar pelo canto da sereia da harmonia entre os homens e confundiu igualdade com igualamento das diferenças, sem questionar as consequências de se colocar as padronizações e homogeneizações como única verdade sobre a produção do bem comum? Abrir os olhos para este 'canto da sereia' - ou fechar os ouvidos - é denunciar o que está em risco no jogo da homogeneização e da idealização do ser humano.

Ainda no movimento de idas e vindas sucessivas acerca da dimensão ético-política, é interessante observar que a atitude de refletir sobre o agir foi um dos temas trazidos nas falas dos apoiadores, através de sentidos como a liberdade de escolha, a suspensão dos julgamentos, o compromisso social, o guiar-se por princípios e a preocupação com as consequências dos atos:

Eu vejo no meu trabalho uma coisa de não julgar, porque é uma área com muito preconceito (...) A gente tende a julgar muito, isto eu percebo que é reflexo da questão da formação. Porque daí tu banalizas, desvalorizas o sofrimento do outro (Pitágoras).

Quando converso com trabalhadores dos serviços, tento me voltar para este papel político dos fiscais, compromisso com a sociedade, de ter produtos de boa qualidade. (...) perder de vista esta dimensão é reduzir área a regras e normas (Pitágoras).

Neste sentido, entendemos a preocupação desses apoiadores em constituir elementos que auxiliem na compreensão e resolução de conflitos de interesses e valores no campo da saúde. Como afirmam Verdi e Caponi,

Para a construção das mudanças necessárias no cotidiano das práticas profissionais de saúde é preciso refletir sobre as implicações éticas das ações dos trabalhadores como agentes morais. É preciso, também, compreender o caráter dinâmico da sociedade como um espaço em permanente disputa de interesses políticos e desejos individuais e coletivos, que envolvem forças díspares, valores diversos e crenças divergentes (Verdi e Caponi, 2005, p. 87).

A gestão cotidiana desses conflitos envolve a análise das incongruências entre os distintos valores norteadores das práticas sanitárias. É neste campo de análise que a bioética tem se proposto a intervir, como campo do conhecimento que se constituiu inspirado pelos diversos contextos sociais em que se expressa a necessidade de instrumentalizar os sujeitos para que possam efetivar tais análises (Schramm e Arreguy, 2005). 
Outro tema identificado a partir da análise da fala dos apoiadores foi o da democratização das relações, associado à desestabilização dos poderes instituídos e à crítica aos modos tradicionais de organização do poder nas instituições. Essas falas remetem a aspectos importantes para essa democratização, como o fomento do protagonismo e da autonomia, a indissociação entre saber e as relações de poder e o exercício da cogestão. Quanto ao protagonismo e à autonomia dos sujeitos, as falas os associaram especificamente a situações em que havia uma dimensão instituinte presente, pela busca da ampliação da capacidade de análise e de uma dimensão coletiva do trabalho.

Estávamos agora discutindo se a penicilina devia ou não ser aplicada na unidade de saúde e, mesmo não trabalhando mais lá, eu comecei a discutir com eles, perguntei se achavam que dava para assumir isto dentro do serviço (Pitágoras).

Ao abordar o tema das iniquidades, a bioética social enfatiza a necessidade de defender um modelo de atenção à saúde pautado em uma ética de empoderamento dos vulnerados, que os fortaleça na capacidade de gestão das próprias vidas. Desde esta perspectiva, o avanço rumo a uma transformação social, que coloque a saúde como direito da pessoa e interesse da comunidade, dar-se-ia mediante a ação política concreta dos sujeitos. A efetivação da democracia dependeria da ação de sujeitos livres e legítimos, sendo o respeito e o reconhecimento das singularidades e diferenças premissas para o exercício democrático e participativo (Kottow, 2011; Garrafa, 2005; Berlinguer, 1987).

A ampliação da capacidade de análise aparece no discurso dos apoiadores como um dos efeitos do processo de formação, mas tampouco parece ser suficiente para alterar o sentimento de impotência diante de alguns contextos, evidenciando lacunas quanto à discussão sobre a perspectiva micropolítica para o exercício do apoio.

A minha forma de ver as coisas mudou bastante, posso considerar que me senti muito afetada com as discussões que tivemos várias vezes, em roda (Tales).

Acho complicado de explicar [a defesa dos direitos]. É algo maior, não é algo que dê para se trabalhar só aqui. Quando se fala do direito dos sujeitos envolvidos, eu acho que tem que ser um trabalho mais de cima pra baixo, mais de Estado. Na instituição é mais difícil de fazer, é um tema mais complicado (Tales).

As compreensões colocadas pelo apoiador acima remetem ao que Campos (2000) diz sobre o exercício do poder, da autonomia, da capacidade de análise e de intervenção, ao afirmar que estes não são homogêneos nos grupos. Tais diferenças derivariam de condições desiguais de desenvolvimento da potencialidade existente em cada sujeito. Para o autor, a ampliação da capacidade 
de análise é condição para maior intervenção sobre a própria realidade. Tal capacidade é ampliada à medida que aumenta a participação no processo decisório e na invenção de novas lógicas e estruturas organizacionais. Os modos tradicionais de gestão se assentam em uma racionalidade hegemônica, fundamentada na concentração de poderes e saberes, e têm nestas assimetrias as condições adequadas para sua reprodução contínua, onde as diferenças são naturalizadas e o desejo dos mais vulnerados ignorado. Os processos de cogestão teriam como objetivo, além de produzir bens ou serviços, garantir espaços e arranjos com função pedagógica e terapêutica, visando a eliminação das diferenças injustas entre os sujeitos, a partir do desenvolvimento das possibilidades individuais (Campos, 2000; 2005).

De modo ainda mais explícito, alguns apoiadores relacionaram a capacidade de exercício do poder ao saber, vendo a ampliação dos saberes como condição-chave para o exercício da autonomia e protagonismo.

Não acredito em autonomia sem conhecimento (...) Fui fazer uma consulta e o médico mandou fazer um exame que eu não conhecia, eu não queria, pelo risco, uma suspeita sem fundamentação, mas não consegui discutir isto com o profissional. Eu não tive autonomia para discutir e pra dizer 'eu não vou fazer' (Pitágoras).

Esse entendimento nos aproxima do pressuposto foucaultiano de que não há relação de poder sem um campo de saber correspondente, e nem um saber que prescinda e não constitua relações de poder. O poder produz saber, o que implica pensar o poder como relação. Ora, a consequência deste pensamento delimita um procedimento investigativo focado nas produções, discursos e representações advindas de uma lógica circunstancial de poder e de saber. A partir das práticas discursivas é possível desvelar os objetos de saber, analisar seu surgimento e quais transformações esses objetos sofrem. Analisar esse discurso implica compreender o modo como ele é usado, seus efeitos, suas formas de controle, o que é excluído, o que é beneficiado, pressupondo que uma prática discursiva é valorizada porque produz verdade (Foucault, 1971; 1995).

Nesta perspectiva, observou-se que alguns apoiadores deram ênfase às relações que o saber estabelece com o poder, seus efeitos e consequências para o trabalho, bem como buscaram articular conhecimento e produção de corresponsabilização:

O desconhecimento contribui para a não responsabilização, porque se a pessoa não sabe como faz o negócio, se exime (Demócrito).

Com conhecimento sobre a atenção e a gestão, as pessoas desenvolvem maior comprometimento com o processo de fazer saúde (Aristóteles). 
Hoje tem pessoas que trabalham mais responsabilizadas com aquela situação: 'eu vou passar o pano porque eu sei que pode dar bactéria, que pode dar infecção'. Elas (as auxiliares de limpeza) se corresponsabilizaram porque se sentiram no processo (Parmênides).

O divórcio entre conhecimento - no sentido moderno de know how - e pensamento foi alvo da preocupação de Arendt (2007), que colocava como consequência desta separação nossa sujeição à condição de 'criaturas desprovidas de raciocínio' e, portanto, à mercê de qualquer técnica ou tecnologia, mesmo que letal. Neste sentido, alguns apoiadores relacionaram as resistências de seus pares e gestores à $\mathrm{PNH}$ como sinal de uma resistência à reflexão, ao pensamento, uma consequência do sentimento cristalizado de descrença na possibilidade de transformação da realidade dos serviços. Isto teria dificultado o aprofundamento das discussões sobre a PNH dentro dos serviços, e ajudado a reforçar a permanência das incompreensões quanto ao sentido de humanização proposto pela política.

Tem um povo que não acredita, então às vezes a gente fomenta a reflexão, mas sem citar a humanização. A resistência em relação à $\mathrm{PNH}$ vem de uma descrença na possibilidade de mudança, os profissionais querem ser vistos pela gestão pra algumas coisas, pra outras, melhor não, pra não sair da inércia (Sócrates).

Eles pensam que a PNH é bobagem. 'Querer humanizar o humano?' É aquela coisa de pensar que a PNH é dar um sorrisinho. Tem que esclarecer bem para eles entenderem melhor todo o processo (Ptolomeu).

A associação da PNH à proposta de 'humanizar o humano' é um dos equívocos mais frequentes ligados à Política. Conforme Sá (2009), o problema estaria na insistência da Política em manter o termo, inadequado para designar o que pretende devido a sua polissemia, que o faz estar por demais associado a crenças da doutrina do humanismo cristão, ou personalismo cristão, que vê o ser humano como um ser intrinsecamente bom.

Nos relatos dos apoiadores também são possíveis de se identificar iniciativas efetivadas por eles no cotidiano dos serviços que buscavam uma aproximação à proposta da cogestão. A subcategoria 'exercício da cogestão' foi delineada a partir de falas que assinalavam o comprometimento e a corresponsabilização, o compartilhamento de poderes e de saberes, a dimensão coletiva do trabalho e a produção do comum como elementos presentes nas experimentações destes apoiadores.

O grupo reunia-se para analisar a situação e buscar uma solução, acontecendo a troca de saberes, a cogestão, a escolha pela melhor alternativa, ocasionando mudanças necessárias e adequações de procedimentos (Plutarco). 
O exercício democrático foi colocado tanto no âmbito das decisões referenciadas ao contexto macro das organizações, e que se efetiva por meio de colegiados e coletivos de gestão, quanto no âmbito da micropolítica, da gestão cotidiana do fazer em saúde e que reverbera sobremaneira na prática clínica:

A autonomia tem de ser de um grupo de pessoas, não só individual. O plano terapêutico individual, eles [os usuários] constroem junto conosco. Não adianta eu sozinha montar uma coisa que ele vai ter que desenvolver para o resto da vida dele (Demócrito).

Este exercício micropolítico de produção de protagonismo, proposto para os diferentes sujeitos, tem potência de contágio, de se infiltrar nas tramas intersubjetivas onde o poder se expressa. Contra um sistema político e econômico que aparta a população dos processos decisórios e da transformação institucional, Berlinguer (1987) reafirma a luta pelo aumento dos poderes locais como essencial para uma decisiva modificação das relações sociais e das posições de poder, da participação coletiva na economia e da valorização da ciência a serviço dos homens.

O poder surge do agir conjunto entre a ação e o discurso, pois se manifesta no pacto efêmero das várias intenções e vontades, de modo que é somente na coexistência entre os homens que o poder político poderá existir. Se a ação política se dá na interação intersubjetiva na qual se referencia, é necessário então articular ação e discurso, pois este último é o veículo da opinião política, sendo capaz de revelar a ação, mas apenas na esfera pública. Enquanto mundo comum, a esfera pública possibilita que as pessoas de uma comunidade se mantenham unidas em torno de algo que as relaciona e as distingue. Conviver no mundo significa ter um mundo de coisas interposto entre os que nele habitam, pois, "como todo intermediário, o mundo ao mesmo tempo separa e estabelece uma relação entre os homens" (Arendt, 2007, p. 61). A ação política, como capacidade de assumir as condições de produção da própria existência, só é possível nesta produção do comum, esta trama produzida no movimento e comunicação das singularidades, das diferenças, e que é sempre fundamentada no reconhecimento do outro.

\section{Considerações finais}

Ao final do estudo, percebemos que a dimensão ética em geral mostrou-se indissociada da dimensão política, relacionando atitudes, princípios e valores que orientam a reflexão e a ação cotidianas de modo a buscar a democratização das relações de poder. Esta reflexão sobre as ações em saúde e os princípios que as norteiam colocou em foco a preocupação dos apoiadores com a intencionalidade ética que anima o seu pensar e fazer. 
O tema do compartilhamento dos poderes, associado pelos apoiadores à consciência da necessidade de participação ativa no processo de produção de saúde nos faz refletir sobre a afirmação de Berlinguer da participação como elemento-chave para a transição subjetiva de um polo de passividade para outro, de protagonismo. O autor toma como referência Amartya Sen, ao afirmar que a renda não pode ser o único indicador de igualdade em uma sociedade: as aptidões e capacidades para converter a renda em ações que promovam saúde são fundamentais para a melhoria dos indicadores de saúde, e o desenvolvimento daquelas é impossível sem a experiência concreta de participação.

É possível concluir que os apoiadores mantiveram a dimensão de responsabilização muito presente, dando maior ênfase à experiência individual e menos a uma produção coletiva de corresponsabilização. É provável que a baixa presença do tema da produção de redes e coletivos nas falas esteja associada a esta fragilidade de uma experimentação mais coletiva do trabalho, apontando a necessidade de se buscar estratégias que problematizem mais amplamente os efeitos do trabalho centrado em práticas individuais para a produção de saúde.

Retomando a hipótese do estudo, que supunha o processo de formação como espaço potente para a reflexão ético-política e sua incorporação à prática cotidiana, concluímos que tal reflexão de fato foi acionada pela formação. Esta, mesmo com as insuficiências apontadas, mostrou-se potente no fomento do debate ético-político, essencial para contribuir na interlocução entre razão e ação, e na transformação dos sujeitos em agentes estratégicos da consolidação da justiça sanitária. As insuficiências da formação, quanto ao entendimento de conceitos trabalhados pela $\mathrm{PNH}$, têm relação tanto com a complexidade destes quanto com sua posição contra-hegemônica no campo da saúde, que demandaria intensos deslocamentos de ordem conceitual e subjetiva. Tal complexidade foi muito reiterada pelos sujeitos do estudo e citada como uma das razões que obstaculizaram uma maior capacidade de operar a política no cotidiano. Na análise dos apoiadores, a duração da formação foi insuficiente para gerar um entendimento e experimentação satisfatórios ainda no seu transcurso, salientando a necessidade de suporte por parte da política no período pós-curso. A vivência da dimensão ético-política foi associada a esta lacuna. Transpareceu nesses relatos a expectativa de que um 'apoio ao apoiador' realizado no pós-curso pela PNH fosse a resposta que faltava para uma maior possibilidade de interferência destes sujeitos nas práticas cotidianas de saúde.

Considerando o baixo número de iniciativas implementadas pelos apoiadores para a constituição de estratégias de superação das lacunas deixadas pela formação e o sentimento de impotência quanto à governabilidade para intervir nas práticas pautadas nas racionalidades gerencial e biomédica, 
pode-se supor que a ação protagonista ainda é objetivo a ser melhor trabalhado na formação para o apoio.

A significativa referência às insuficiências da PNH quanto a sua difusão e implementação - vista como uma das razões da resistência à política nos serviços - necessita de análise mais profunda acerca de seus condicionantes e efeitos. É importante assinalar que os resultados desta investigação precisam ser analisados e interpretados à luz das singularidades territoriais que marcaram a experiência de formação em questão. Tendo isto em perspectiva, é possível afirmar que as ações formativas estruturadas em torno da reflexão e ação ética e politizada demandam diferentes estratégias para alcance da dimensão processual deste tipo de formação, devendo haver ênfase na construção de ações coletivas locais de apoio às intervenções.

Por fim, o estudo permitiu evidenciar a formação como estratégia que pode assumir maior centralidade no agenciamento da transformação social quando a perspectiva ético-política a transversaliza, originando o encontro de forças instituintes que produzem não só novos modos de fazer, mas também novos sujeitos.

\section{Colaboradores}

Maria Claudia Souza Matias e Marta Inez Machado Verdi conceberam a pesquisa. Maria Claudia colheu e analisou os dados, e redigiu o artigo. Marta e Mirelle Finkler orientaram a pesquisa e participaram da revisão crítica do manuscrito. Não há conflito de interesses. 
Resumen $\mathrm{Al}$ afirmarse como política pública fundamentada en el paradigma ético, estético y político, la Política Nacional de Humanización introdujo un nuevo sentido para la propuesta de humanización de la salud: un sentido contrahegemónico, asociado a la comprensión de la vida como apertura y multiplicidad. Frente al desafío de operar un concepto tan innovador y contrario a las prácticas tradicionales, este estudio buscó discutir la comprensión y la vivencia que apoyadores institucionales formados por la Política Nacional de Humanización tenían de la dimensión ética y política contenida en la propuesta. El objeto de esta investigación se indagó a la luz de un abordaje metodológico cualitativo, de carácter exploratorio y descriptivo, teniendo como sujetos los egresados de un proceso de formación de apoyadores institucionales realizado en 2009 en Santa Catarina, Brasil. Por medio de entrevistas e investigación documental, se obtuvieron como resultados una comprensión de la dimensión fundamentada en la valorización de los sujetos y en la democratización de las relaciones. Las vivencias y experimentaciones, no obstante, fueron marcadas por obstáculos y desafíos, como el de la concentración de poder en las instituciones y el de la fragilidad del modelo de atención a la salud, todavía orientado en las racionalidades gerencial y biomédica. También se interpusieron como desafío dificultades relacionadas con la comprensión de algunos conceptos de la Política y a los modos como se ha venido organizando en los servicios de salud y dentro de la federación.

Palabras clave ética, política de salud; humanización de la asistencia; educación en salud.

\section{Notas}

1 Ministério da Saúde, Secretaria de Atenção à Saúde, Política Nacional de Humanização, Brasília, Brasil.

<claudiamatias2005@yahoo.com.br>

Correspondência: Rua Victor Konder, 55 apto. 401, Victor Konder, CEP 89012-170, Blumenau, Santa Catarina, Brasil.

2 Universidade Federal de Santa Catarina, Centro de Ciências da Saúde, Departamento de Saúde Pública, Florianópolis, Santa Catarina, Brasil.

<verdi@mboxl.ufsc.br>

3 Universidade Federal de Santa Catarina, Centro de Ciências da Saúde, Departamento de Saúde Pública, Florianópolis, Santa Catarina, Brasil.

$<$ mirellefinkler@yahoo.com.br>

4 Texto inédito que apresenta os resultados obtidos em pesquisa de dissertação de mestrado intitulada A dimensão ético-politica da humanização no discurso de egressos da formação de apoiadores institucionais de Santa Catarina, cujo projeto foi aprovado pelo Comitê de Ética da Universidade Federal de Santa Catarina (UFSC), sob o n. 21561/2012. O estudo foi parte de uma pesquisa maior, financiada pelo CNPq (processo n. 454758/2012-0/UFSC) e pelo Ministério da Saúde - Proadi-Sipar (n. 25000.181244/2011-76).

5 Realizado no âmbito do projeto “Desenvolvimento de Técnicas de Formação, Operação e Gestão de Serviços de Saúde nos Territórios do Rio Grande do Sul, Santa Catarina e São Paulo", firmado entre o Ministério da Saúde, a Associação Hospitalar Moinhos de Vento, a Universidade Federal do Rio Grande do Sul, a UFSC e a Universidade Estadual Paulista. 


\section{Referências}

ARENDT, Hanna. A condição humana. Rio de Janeiro: Forense Universitária, 2007.

AYRES, José R. Organização das ações de atenção à saúde: modelos e práticas. Saúde e Sociedade, São Paulo, v. 18, n. 2, p. 11-23, abr.-jun. 2009.

BARDIN, Lawrence. Análise de conteúdo. Lisboa: Edições 70, 2010.

BARROS, Maria E. B. Desafios ético-políticos para a formação dos profissionais de saúde: transdisciplinaridade e integralidade. In: PINHEIRO, Roseni; MATTOS, Ruben A.; CECCIM, Ricardo B. (orgs.). Ensinar saúde: a integralidade e o SUS nos cursos de graduação na área da saúde. Rio de Janeiro: Cepesc, 2006. p. 131-151.

BENEVIDES, Regina; PASSOS, Eduardo. Humanização na saúde: um novo modismo? Interface: Comunicação, Saúde, Educação, Botucatu, v. 9, n. 17, p. 389-394, 2005.

BERLINGUER, Giovanni. Ética da saúde. São Paulo: Hucitec, 1996.

BERLINGUER, Giovanni. Medicina e política. 3. ed. São Paulo: Hucitec, 1987.

BRASIL. Ministério da Saúde. Política Nacional de Humanização. Documento-base para gestores e trabalhadores do SUS. 4. ed. Brasília: Ministério da Saúde, 2008.

CAMPOS, Gastão W. S. Um método para análise e cogestão de coletivos. São Paulo: Hucitec, 2000.

CAMPOS, Gastão W. S. Humanização na saúde: um projeto em defesa da vida? Interface: Comunicação, Saúde, Educação, Botucatu, v. 9, n. 17, p. 389-406, mar./ago., 2005.

DESLANDES, Sueli. Análise do discurso oficial sobre a humanização da assistência hospitalar. Ciência \& Saúde Coletiva, Rio de Janeiro, v. 9, n. 1, p. 7-14, 2004.
FOUCAULT, Michel. A ordem do discurso. Paris: Gallimard, 1971.

FOUCAULT, Michel. O sujeito e o poder. In: DREYFUS, Hubert; RABINOW, Paul. Michel Foucault, uma trajetória filosófica. Rio de Janeiro: Forense Universitária, 1995, p. 231-249.

FUGANTI, Luís. Saúde, desejo e pensamento. In: LANCETTI, Antonio (org.). Saúde e loucura. São Paulo: Hucitec, 1990.

GARRAFA, Volnei. Introdução à Bioética. Revista Hospital Universitário UFMA, São Luís, v. 6, n. 2, p. 9-13, 2005.

GUATTARI, Felix. Caosmose: um novo paradigma estético. São Paulo: Editora 34, 1992.

GUIZARDI, Francine; CAVALCANTI, Felipe. Por um mundo democrático produzido democraticamente (ou: o desafio da produção do comum): contribuições a partir da experiência do Sistema de Saúde Brasileiro. Lugar comum: Estudos de Mídia, Cultura e Democracia, Rio de Janeiro, n. 27, p. 103-124, jan.-abr. 2009.

HECKERT, Ana L. C.; PASSOS, Eduardo H.; BARROS, Maria E. B. Um seminário dispositivo: a humanização do Sistema Único de Saúde (SUS) em debate. Interface: Comunicação, Saúde, Educação, São Paulo, v. 13, n. 1, p. 493-502, 2009.

KOTTOW, Miguel. Bioética pública: una propuesta. Bioética, v. 19, n. 1, p. 61-76, 2011.

NEVES, Claudia A. B.; MASSARO, Altair. Biopolítica, produção de saúde e um outro humanismo. Interface: Comunicação, Saúde, Educação, Botucatu, v. 13, supl. 1, p. 503-14, 2009.

OLIVEIRA, Gustavo N. Devir apoiador: uma cartografia da função apoio. 175 fls. Tese (Doutorado em Saúde Coletiva) - Universidade Estadual de Campinas, Faculdade de Ciências Médicas, Campinas. 2011. 
PASCHE, Dario. Desafios éticos para a consolidação do SUS. In: CAPONI, Sandra; VERDI, Marta; BRZOZOWSKI, Fabíola S.; HELLMANN, Fernando. Medicalização da vida: ética, saúde pública e indústria farmacêutica. Palhoça: Unisul, 2010. p. 381-389.

PASCHE, Dario; PASSOS, Eduardo. Apresentação. In: BRASIL. Formação e intervenção. Brasília: Ministério da Saúde, Cadernos HumanizaSUS, v. 1. p.5-10, 2010.

PAULON, Simone M.; CARNEIRO, Mara L. F. A educação a distância como dispositivo de fomento às redes de cuidado em saúde. Interface: Comunicação, Saúde, Educação, Botucatu, v. 13, n. 1, p. 749-757, 2009.

PAULON, Simone M.; ROMAGNOLI, Roberta C. Pesquisa-intervenção e cartografia: melindres e meandros metodológicos. Estudos e Pesquisas em Psicologia, Rio de Janeiro, v. 10, n. 1, p. 18-25, abr. 2010.

PAVAN, Cleusa et al. Documento orientador da política de formação da PNH. In: BRASIL. Formação e intervenção. Brasília: Ministério da Saúde, Cadernos HumanizaSUS, v. 1, p. 73-94, 2010.

ROLNIK, Suely. Pensamento, corpo e devir. Uma perspectiva ético/estético/política no trabalho acadêmico. Cadernos de Subjetividade, São Paulo, v. 1, n. 2, p. 241-251, 1993.
SÁ, Marilene C. A fraternidade em questão: um olhar psicossociológico sobre o cuidado e a 'humanização' das práticas de saúde. Interface: Comunicação, Saúde, Educação, Botucatu, v. 13, supl. 1, p. 651-664, 2009.

SCHRAMM, Fermin R.; ARREGUY, Euclydes E. Bioética do Sistema Único de Saúde/SUS: uma análise pela Bioética da Proteção. Revista Brasileira de Cancerologia, Rio de Janeiro, v. 51, n. 2, p. 117-123, 2005.

VERDI, Marta; CAPONI, Sandra. Reflexões sobre a promoção da saúde numa perspectiva bioética. Texto Contexto Enfermagem, Florianópolis, v. 14, n. 1, mar. 2005.

ZOBOLI, Elma L. C. P. Bioética e atenção básica: para uma clínica ampliada, uma bioética clínica amplificada. O Mundo da Saúde, São Paulo, v. 33, n. 2, p. 195-204, 2009.

ZOBOLI, Elma L. C. P. Desafios éticos para a consolidação do SUS. In: CAPONI, Sandra; VERDI, Marta; BRZOZOWSKI, Fabíola S.; HELLMANN, Fernando. Medicalização da vida: ética, saúde pública e indústria farmacêutica. Palhoça: Unisul, 2010. p. 373-380.

Recebido em 07/01/2013

Aprovado em 31/01/2015 